\title{
Platelets and COVID-19
}

\author{
Anne-Katrin Rohlfing ${ }^{1}$ Dominik Rath ${ }^{1} \quad$ Tobias Geisler $^{1} \quad$ Meinrad Gawaz ${ }^{1}$ \\ ${ }^{1}$ Department of Cardiology and Angiology, University Hospital \\ Tübingen, Eberhard Karls Universtität Tübingen, Tübingen, Germany \\ Hamostaseologie 2021;41:379-385.

\begin{abstract}
Address for correspondence Meinrad Gawaz, Prof. Dr. med., Department of Cardiology and Angiology, University Hospital Tübingen, Otfried-Müller-Straße 10, 72076 Tübingen, Germany (e-mail: meinrad.gawaz@med.uni-tuebingen.de).
\end{abstract}

\section{Abstract}

Keywords

- SARS-CoV-2

- COVID-19

- platelets

- thrombosis

- thrombocytopenia

\section{Zusammenfassung}

Keywords (German)

- SARS-CoV-2

- COVID-19

- Plättchen

- Thrombose

- Thrombozytopenie
In 2019 first reports about a new human coronavirus emerged, which causes common cold symptoms as well as acute respiratory distress syndrome. The virus was identified as severe acute respiratory syndrome coronavirus 2 (SARS-CoV-2) and severe thrombotic events including deep vein thrombosis, pulmonary embolism, and microthrombi emerged as additional symptoms. Heart failure, myocardial infarction, myocarditis, and stroke have also been observed. As main mediator of thrombus formation, platelets became one of the key aspects in SARS-CoV-2 research. Platelets may also directly interact with SARS-CoV-2 and have been shown to carry the SARS-CoV-2 virus. Platelets can also facilitate the virus uptake by secretion of the subtilisin-like proprotein convertase furin. Cleavage of the SARS-CoV-2 spike protein by furin enhances binding capabilities and virus entry into various cell types. In COVID-19 patients, platelet count differs between mild and serious infections. Patients with mild symptoms have a slightly increased platelet count, whereas thrombocytopenia is a hallmark of severe COVID-19 infections. Low platelet count can be attributed to platelet apoptosis and the incorporation of platelets into microthrombi (peripheral consumption) and severe thrombotic events. The observed excessive formation of thrombi is due to hyperactivation of platelets caused by the infection. Various factors have been suggested in the activation of platelets in COVID-19, such as hypoxia, vessel damage, inflammatory factors, NETosis, SARS-CoV-2 interaction, autoimmune reactions, and autocrine activation. COVID-19 does alter chemokine and cytokine plasma concentrations. Platelet chemokine profiles are altered in COVID-19 and contribute to the described chemokine storms observed in severely ill COVID-19 patients.

In 2019 wurden erste Berichte über ein neuartiges Coronavirus bekannt, welches bei Menschen Erkältungssymptome aber auch ein akutes Lungenversargen (ARDS) auslösen kann. Das Virus wurde als SARS-CoV-2 eingeordnet und schwere Thrombosen, wie z.B. tiefe Venenthrombosen und Lungenembolien, sowie Mikrothromben als zusätzliche Symptome identifiziert. Herzinfarkte, Myokarditis sowie Schlaganfälle wurden ebenfalls beobachtet. Als einer der Hauptmediatoren der Thrombusbildung wurden Thrombozyten schnell zu einem Fokus der SARS-CoV-2 Forschung. Blutplättchen können wahrscheinlich direkt mit SARS-CoV-2 interagieren und es wurde gezeigt das sich Viruspartikel im Zytosol von Thrombozyten befinden können. Thrombozyten können darüber hinaus die Aufnahme des Virus erleichtern, indem sie die subtilisin-like received

June 22, 2021

accepted after revision

August 11, 2021 (c) 2021. Thieme. All rights reserved. Georg Thieme Verlag KG,

Rüdigerstraße 14,

70469 Stuttgart, Germany
DOI https://doi.org/

10.1055/a-1581-4355. ISSN 0720-9355. 
proprotein convertase furin sezernieren, welche das Spike Protein von SARS-CoV-2 Viren spaltet und dadurch die Bindungskapazität des Proteins an zelluläre Rezeptoren erhöht. Die Thrombozytenzahl wird durch eine Covid-19 Infektion beeinflusst. Patienten mit milden Symptomen zeigen leicht erhöhte Thrombozytenwerte, wohingegen eine Thrombozytopenie ein wichtiges Merkmal einer schweren Erkrankung ist. Diese geringe Thrombozytenzahl kann auf eine erhöhte Apoptose sowie den Einschluss von Thrombozyten in Mikrothromben (peripherer Verbrauch) oder massive Thrombosen zurückgeführt werden. Die beobachtete massive Bildung von Thromben erfolgt auf Grund einer Covid-19 induzierten Hyperaktivierung von Thrombozyten. Verschiedene Faktoren können Thrombozyten während einer Covid-19 Infektion aktivieren, dazu zählen Hypoxie, Gefäßschäden, Entzündungsmarker, NETosis, direkte SARS-CoV-2 Interaktionen, Autoimmunreaktionen sowie eine autokrine Aktivierung. Zudem verändert Covid-19 die Chemokin- und Zytokin-Konzentrationen im Blutplasma. Auch das Chemokin Profil von Thrombozyten ist in Covid-19 Patienten verändert und trägt stark zu dem in schwer kranken Patienten beobachteten Chemokinsturm bei.

\section{Introduction}

The severe acute respiratory syndrome coronavirus 2 (SARSCoV-2) belongs to the coronavirus family, which was first discovered in 1960. The first four human coronavirus strains discovered-229E (HCoV-229E), HKU1 (HCoV-HKU1), NL63 (HCoV-NL63), and OC43 (HCoV-OC43)-are known to cause a common cold in healthy individuals. In 2003, a new coronavirus strain, the SARS-CoV, was first described in China and in 2012 the Middle East respiratory syndrome coronavirus (MERS-CoV) was initially detected in Saudi Arabia. Both strains cause severe respiratory tract infections and, in case of MERS, had an extremely high death rate (34\%). These outbreaks were caused by zoonosis probably originating from bats. Reservoirs for coronaviruses have been identified in bats, predominantly in Asia and also in Europe (e.g., Romania). Both the SARS-CoV and MERS-CoV epidemic revealed coronaviruses as a risk to human health and introduced a first bout of scientific research into coronaviruses in general. In 2019, a new human coronavirus was discovered in China, again probably originating from bat populations. Shortly after, the virus was established as SARS-CoV-2 and the outbreak was declared a pandemic by the World Health Organization. Until the end of March 2021, more than $135,000,000$ cases of coronavirus disease 2019 (COVID-19) and more than 2,930,000 deaths have been reported worldwide. First reports of the coronavirus disease termed "COVID-19" listed common cold symptoms and also a high number of severely ill patients with acute respiratory distress syndrome (ARDS) and deaths caused by acute lung injuries and hypoxemic respiratory failure. Shortly after, severe thromboembolic events were reported in critically ill COVID-19 patients. These findings were not surprising as virus infections are often associated with systemic inflammation and changes in hemostasis (e.g., platelet activation, thrombocytopenia) and coagulation (triggered by thrombin activation among others). The first reports about severe thromboembolic events have been proven correct by postmortem examinations and also in some cases documented as cause of death. ${ }^{1}$ Deep vein thrombosis, pulmonary embolism including microthrombi in small arteries, and capillaries of lung tissue are listed in these reports. The heart, the brain, the liver, and the kidneys are also highly perceptible for microthrombi formation in COVID-19 patients. Heart failure, myocardial infarction, myocarditis, and cardiac arrhythmias have also been observed. Significantly elevated levels of Ddimer, a fibrin degradation product, in the plasma accompanied theses first findings. ${ }^{2,3}$ These significantly high levels of D-dimers in the plasma are correlated with severe COVID-19 and massive thrombotic events. ${ }^{3-6}$ These results were making platelets and thrombus formation one of the main focal points in COVID-19 research. Especially considering the overlap of risk factors for COVID-19 and patients with preexisting cardiovascular diseases and/or obesity, diabetes mellitus, hypertension, and advanced age that are prone to thromboembolic events.

\section{SARS-CoV-2 Interaction with Platelets}

Platelets, also called thrombocytes, are small anucleated cell fragments $(2-4 \mu \mathrm{m})$ shed and liberated into the blood stream by megakaryocytes. These small oblate spheroid fragments have a short live span of 8 to 9 days. Their main function is to initiate a first cellular response to vascular injuries and thrombosis. Recently, platelets have been elevated from simple cell fragments to important mediating factors in the blood, when more platelet functions, such as protein synthesis, autophagy, and apoptosis, had been identified. Platelets do interact with numerous cell types in the blood and the surrounding endothelium and they are thereby capable to connect the immune system with thrombotic events especially via the release of various potent cytokines and chemokines. They thereby are key mediators of inflammation. ${ }^{7}$ Blood drawn from COVID-19 patients does contain 
SARS-CoV-2 and is considered potentially infectious. ${ }^{3,8-12}$ High mRNA levels of SARS-CoV-2 in the blood of patients are also positively correlated with severe COVID-19 infections. ${ }^{11}$ Traces of SARS-CoV-2 mRNA were detected in isolated platelets by RT-qPCR and virions have been depicted within platelet sections by electron microscopy techniques. ${ }^{3,11,12}$ Other investigations were not able to verify these results. ${ }^{13}$ Interestingly, Zaid et al described an age discrepancy in the presence of SARS-CoV-2 mRNA measured by qPCR in platelet isolates. ${ }^{3}$ SARS-CoV-2 mRNA-positive platelet samples were more often collected from older COVID-19 patients compared with younger COVID-19 patients. These findings are within the overall picture that SARS-CoV-2 infections are in general more severe in older patients and are more likely to have a negative outcome.

However, whether platelets are even able to interact and internalize SARS-CoV-2 is still controversially discussed. Platelets can take up and degrade viruses such as influenza viruses or human immunodeficiency viruses (HIVs) and therefore maybe considered as a part of the innate immune response. But the main cell entry receptor (e.g., in airway epithelial cells) for SARS-CoV-2 has been identified as angiotensin-converting enzyme 2 (ACE2). ACE2 is expressed on the surface of multiple immune cells like monocytes and macrophages as well as in respiratory and vascular endothelial cells. ${ }^{14-16}$ The expression of ACE2 in platelets and megakaryocytes is still disputed. Manne et al were not able to detect traces of ACE2 mRNA in human platelets or detect the ACE2 protein by proteome assays and immunocytochemistry staining. ${ }^{17}$ In contrast, Zaid et al and Zhang et al were able to detect ACE2 mRNA and perform immunofluorescence staining of ACE2 in human and murine platelets. ${ }^{3,11}$ Numerous factors can contribute to these contrasting findings such as timing and origin of the blood. ACE2 could be internalized and degraded after binding to SARS-CoV-2. Also, mRNA levels could be affected by an acute infection. Manne et al and Zaid et al did indeed use blood from hospitalized COVID-19 patients. ${ }^{3,17}$ In addition, the isolation procedure, which has been different between the studies, might contribute to the varying outcome.

Alternative receptors that could bind SARS-CoV-2 and promote entry into platelets are CD147 (basigin, EMMPRIN), CD26, integrins, and endosomal toll-like receptor-mediated

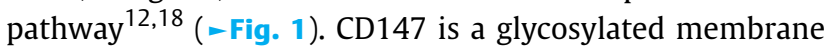
protein, expressed in several blood cells including platelets and has been described as a possible entry vector for SARSCoV-1, HIV, and measles. ${ }^{12}$ The SARS-CoV-2 spike protein contains an RGD motif (arginine-glycine-aspartate) in the receptor-binding domain near the distal dip, which is frequently utilized by viruses (e.g., herpes simplex virus or Epstein-Barr virus) to bind integrin proteins. ${ }^{19,20}$ A homologous KGD sequence has been detected in the SARS-CoV-1 spike protein. ${ }^{19}$ The RGD domain is identical to the RGD sequence in the $\alpha$-chain of fibrin. Platelets express and present several integrin proteins on their cellular surface, such as integrin $\alpha$ IIb $\beta 3$ that binds to the RGD sequence

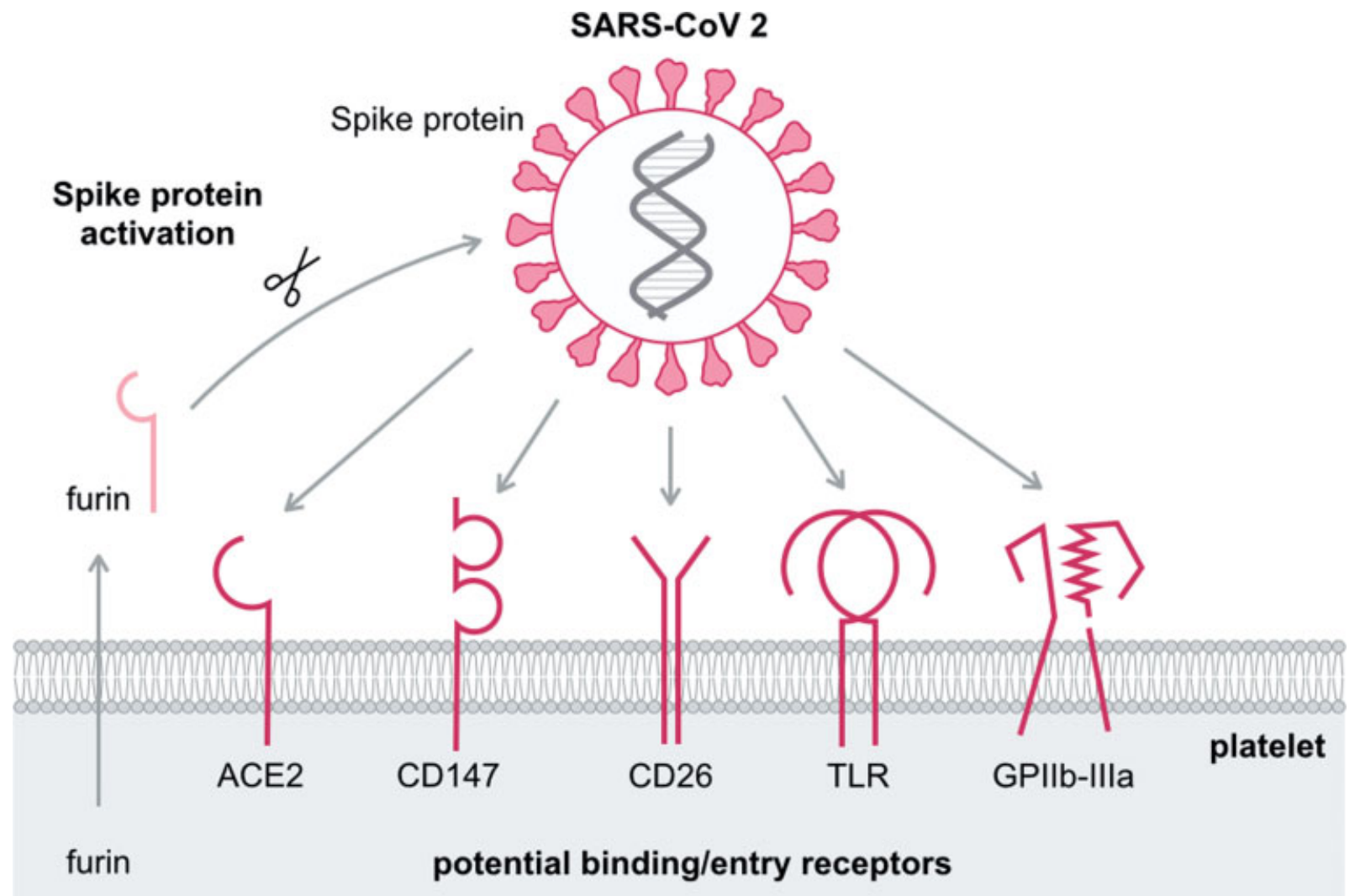

Fig. 1 Various receptors could mediate severe acute respiratory syndrome coronavirus 2 (SARS-CoV-2) binding and cell entry into platelets. Platelet-derived furin can facilitate the cell entry by cleavage and activation of the SARS-CoV-2 spike protein. 
within fibrin. These integrins, therefore, could allow virion binding to the surface of platelets or even enable their entry into the cytoplasm. ${ }^{19,20}$ Incubation of washed platelets with SARS-CoV-2 spike protein or virus particles caused an enhanced platelet aggregation and ATP release upon agonist activation compared with untreated controls but do not independently induce aggregation..$^{11}$ SARS-CoV-2 spike protein did similarly increase thrombus formation in flow chamber experiments with whole blood from ACE2 transgenic mice compared with wild-type mice. ${ }^{11}$ These results demonstrate a direct interaction of virions with platelets, but they do not prove virus uptake by platelets.

However, the presence of SARS-CoV-2 mRNA and virus particles in platelets could also be explained by SARS-CoV-2 infection of megakaryocytes. ${ }^{21}$ Megakaryocytes have an overlapping receptor stock. Therefore, the earlier-described entry vectors can be applied to megakaryocytes as well as platelets. In addition, megakaryocytes are able to engulf hemopoietic cells and thus take up virus particle. mRNA and virions could consequently be diverted from megakaryocytes into platelets during the shedding of the cell fragments into the blood stream. In addition, platelets have the ability to assimilate proteins, vesicles, and other cell components by themselves. Hence, platelets could fuse with extracellular vesicles containing virus particles or mRNA shed from infected cell such as epithelial cells. ${ }^{12}$

The SARS-CoV-2 virus binds to its target cell via its spike protein, which protrudes from the virus surface. This binding initiates the virus fusion with its target cell. Furthermore, viral attachment of SARS-CoV-2 is facilitated by various endogenous membrane bound and circulating proteases and convertases, such as the subtilisin-like proprotein convertase furin, causing severe clinical manifestations during infection. ${ }^{22-25}$ Furin is expressed ubiquitously and regulates a variety of physiological functions and thus is involved in the blood clotting and complement system as well as in the cleavage of membrane receptors, viral-envelope glycoproteins, and bacterial exotoxins. ${ }^{26}$ Furin has been described to play a pivotal role in cardiovascular disease and cardiovascular risk factors such as diabetes mellitus. ${ }^{27}$ Additionally, furin is linked to atheroprogression. The serine protease TMPRSS2 and the subtilisin-like proprotein convertase furin are able to cleave the SARS-CoV-2 spike protein. High furin plasma levels are also a marker for a poor prognosis in severely ill COVID-19 patients. ${ }^{28}$ TMPRSS2 expression was not detected in human platelets. ${ }^{3}$ However, Langnau et al recently established the presence of furin in platelets by Western blot analysis as well as immunofluorescence. ${ }^{28}$ Activated platelets secret furin and are a possible source for furin (-Fig. 1). Platelets can transport furin into the microenvironments of the lung and the heart where platelets, epithelial cells, and SARS-CoV-2 virions meet, and can thereby facilitate the virus entry in various cell types. The furin release is thrombin-dependent and is mediated via the PAR1 or PAR4 receptor. But the kinetics between the two receptors differs. PAR1 responds to quite low thrombin concentrations, whereas PAR4 needs a strong activation signal and might be a back-up system for furin release. To summarize, platelets are in all probability involved in the spike protein activation and thereby facilitate the SARS-CoV-2 entry into various cell types and infection.

\section{Platelet in COVID-19 Infection}

Alterations of the blood platelet count have been reported in patients with an acute COVID-19 infection. ${ }^{29}$ Severely ill patients often exhibit a thrombocytopenia, whereas unlike in other respiratory diseases such as influenza, slightly elevated platelet counts have been measured in patients with mild symptoms. ${ }^{11,29,30}$ Patients with a severe COVID-19 infection also exhibit a low plateletcrit (PTC) and an increased mean platelet volume, platelet distribution width, and platelet large cell ratio. ${ }^{11,31}$ The megakaryocyte count in bone marrow can be increased as well. Furthermore, COVID-19 patients exhibit an abnormal megakaryocytes distribution and proplatelet formation (e.g., in the microvasculature and tissue of the lung, heart, and/or kidney). These diametrically opposed results in platelet count may be explained by the extensive manifestation of thrombotic events in critically ill COVID-19 patients, ranging from the occurrence of microthrombi in several tissues (e.g., lung, heart, liver, or kidney) to massive ischemic events culminating in thromboembolism, myocardial infarction, or stroke..$^{32}$ Another recently described phenomenon is the antibody-induced apoptosis of platelets in COVID19 patients mediated by immunoglobulin $\mathrm{G}(\mathrm{IgG})$ antibodies via the Fcy-receptor IIA (immunoreceptor tyrosine-based activation motif [ITAM]) on the platelet surface. ${ }^{33}$ This process is caused by a SARS-CoV-2-induced autoimmune reaction against surface receptors of platelets and there might be similarities between the observed autoimmune response in COVID patients and the rare thrombotic events after the immunization with certain SARS-CoV-2 vaccines (e.g., AstraZeneca or Johnson \& Johnson) and the heparin-induced thrombocytopenia. Until now disintegration of the platelet mitochondrial membrane, high cytosolic calcium, and enhanced phosphatidylserine presentation have been identified as players in these apoptotic events. ${ }^{33,34}$ These processes can explain the low platelet count in the blood as platelets are bound in thrombotic events or disintegrate by apoptosis and are thereby missing in the peripheral blood. The increase in the systemic megakaryocyte count and an abnormal distribution might be a mechanism to counteract the acute loss of platelets.

The natural and main function of platelets is to initiate the first response to vessel damages. The elevation of epithelial injuries (e.g., collagen, thrombin, or adenosine diphosphate in the blood plasma) does activate platelets, which in turn releases microvesicles and granules containing numerous chemokines and cytokines. These inflammatory signals attract immune cells and induce thrombus formation, the first steps toward vessel damage repair.

Severely ill COVID-19 patients display a severe thrombocytopathy. Virus-induced respiratory tract infections like an acute SARS-CoV-2 infection are often associated with platelet activation and characteristic coagulopathy and often occur early during infection. ${ }^{3,35-38}$ Platelets of COVID-19 
patients are generally hyperactivated, marked by significantly elevated P-selectin surface expression already at the time of hospital admission. ${ }^{2,28,39}$ Several factors contribute to this hyperactive state $2,28,40$ and it is distinct from other ARDSs such as influenza-induced ARDS. ${ }^{41}$ The uncontrolled hyperinflammation in COVID-19 reflects in the hyperactivation of platelets and is accompanied by a hypofibrinolysis. ${ }^{42} \mathrm{Al}-$ though COVID-19 is associated with elevated D-dimer levels, hypofibrinolysis may be caused by an accelerated coagulation cascade and factor consumption. However, this hypothetic explanation needs further evaluation. Patients are at risk to develop progressive respiratory failure, multipleorgan failure, and death. Severely ill COVID-19 patients often have preexisting cardiovascular conditions, are obese, have diabetes mellitus, have hypertension, or are of advanced age. All these conditions are commonly known to affect/induce platelet activation. Also, the COVID-19-induced hypoxia in critically ill patients does have a strong system-wide effect and is prone to affect platelets. Furthermore, SARS-CoV-2 virus itself may activate platelet aggregation and thrombus formation through the previously described pathways, such as interaction of the spike protein with integrins, e.g. integrin $\alpha$ IIbß3 (GPIIb-IIIa), via the RGD motif.. ${ }^{11,19}$ The SARS-CoV-2 virus carries hundreds of spike protein trimers, each monomer containing three RGD motifs. Similar virus-induced coagulation does occur in hantavirus infections, which utilize integrin $\alpha I I b \beta 3$ binding to recruit platelets to endothelial walls and form thrombi, even though integrin $\alpha \operatorname{Ilb} \beta 3$ recruiting does not involve an RGD motif in hantaviruses. ${ }^{19}$ Interestingly, anti-spike protein antibodies can suppress SARSCoV-2-induced platelet activation in vitro. ${ }^{11}$ It has been recognized that patients with severe acute respiratory failure show enhanced pathophysiological signs of inflamed endothelium in the pulmonary microcirculation (endothelialitis). ${ }^{43}$ Activation of platelets is a major trigger for endothelial dysfunction. ${ }^{44,45}$ Enhanced platelet activation and subsequent endothelial reactions are likely to promote microcirculatory arrest in organ failure. ${ }^{46}$

In addition, the tissue damage caused by the virus especially in the lung epithelium can further activate platelets. Tissue damage factors such as von-Willebrand factor (vWF), fibrinogen, PAI 1, soluble thrombomodulin, or angiopoietin are elevated in plasma from COVID-19 patients. ${ }^{2,30,47}$ Especially vWF and fibrinogen together with D-dimer and Pselectin are vital for the development of coagulopathies. In addition, NETosis has also been identified as a factor in the inflammatory response to SARS-CoV-2 as well as platelet activation. ${ }^{32,48}$ NET formation is also associated with microthrombi formation and SARS-CoV-2 induced significantly high plasma levels of platelet factor 4 (PF4) and RANTES might contribute to NETosis. ${ }^{48}$ Antibody-induced platelet aggregation has been detected in severely ill COVID-19 patients, ${ }^{33}$ similar to the IgG-induced apoptosis of platelets via the Fcr-receptor IIA (ITAM). All these described aspects contribute in different degrees to the hyperactivated state of platelets in COVID-19 patients.

The system-wide inflammation caused by the virus is reflected in increased inflammatory markers in the blood plasma (e.g., complement factors, C-reactive protein, or ferritin). ${ }^{29}$ A correlation between chemokines and other inflammatory markers has also been observed (e.g., IL-6 levels seem to be correlated with the fibrinogen concentration in blood plasma from COVID-19 patients). Cytokine and growth factors in general are also significantly altered in the blood plasma of COVID-19 patients. Zaid et al used a multiplex system to measure the plasma concentrations of 48 cytokines and growth factors. From 48 cytokines measured, 13 were significantly increased in patients with a mild COVID-19 infection and two significantly downregulated compared with healthy controls. In severely ill patients, 27 out of 48 cytokines were significantly upregulated and 2 downregulated. In parallel, cytokine level in platelet lysates from COVID-19 patients were significantly downregulated compared with healthy controls. ${ }^{3}$ In addition, circulating platelet/leukocyte co-aggregates correlate with plasma levels of cytokines/chemokines such as IL-6, CCL2, and CXCL10, and activation of platelets is associated with CCL5 and elevation of systolic pulmonary artery pressure. ${ }^{28} \mathrm{An}$ increased PF4 plasma level in COVID-19 patients further underlined an elevated $\alpha$ - and dense granule release from platelets. One intracellular key regulator of $\alpha$ - and dense granule release is the protein kinase $\mathrm{C} \boldsymbol{\delta}(\mathrm{PKC} \boldsymbol{\delta})$. In vitro stimulation experiments with platelets revealed an enhanced phosphorylation of PKC $\boldsymbol{\delta}$ samples from COVID-19 patients, indicating a sensitization of platelet activations/secretion pathways. ${ }^{3}$

These results underline the importance of the inflammatory response to a SARS-CoV-2 infection and the correlation of cytokine plasma levels and the occurrence of cytokine storms with the severity of a SARS-CoV-2 infection.

Activated platelets can also increase their own activation through autocrine pathways. Cytokines and chemokines released from granules do attract immune cells and also act as a positive feedback loop on platelets themselves. Besides an effect in autoactivation, platelet-derived extracellular vesicles (PLT-EVs) even qualify as diagnostic parameter for a SARS-CoV-2 infection. PLT-EVs are significantly elevated in SARS-CoV-2 patients with severe COVID-19 compared with healthy controls. ${ }^{3,49}$ Hyperactivated platelets do significantly aggregate with themselves or other cell types such as neutrophils or monocytes and show increased thrombus formation abilities. ${ }^{28,50}$ Hyperactive platelets together with the massive cell damage caused by the SARS-CoV-2 and an impaired fibrinolysis in patients lead to severe thrombotic events in critically ill COVID-19 patients and the pathological outcome observed in postmortem examinations. Other cell types, especially immune cells, identify hyperactivated platelets under pathological conditions. This can lead to platelet consumption and clearance, another factor contributing to the observed thrombocytopenia in critically ill patients.

\section{Conclusion}

With high probability, platelets do interact with SARS-CoV-2 virions and have been shown to carry the SARS-CoV-2 virus. Platelets can also facilitate the virus uptake by secretion of 


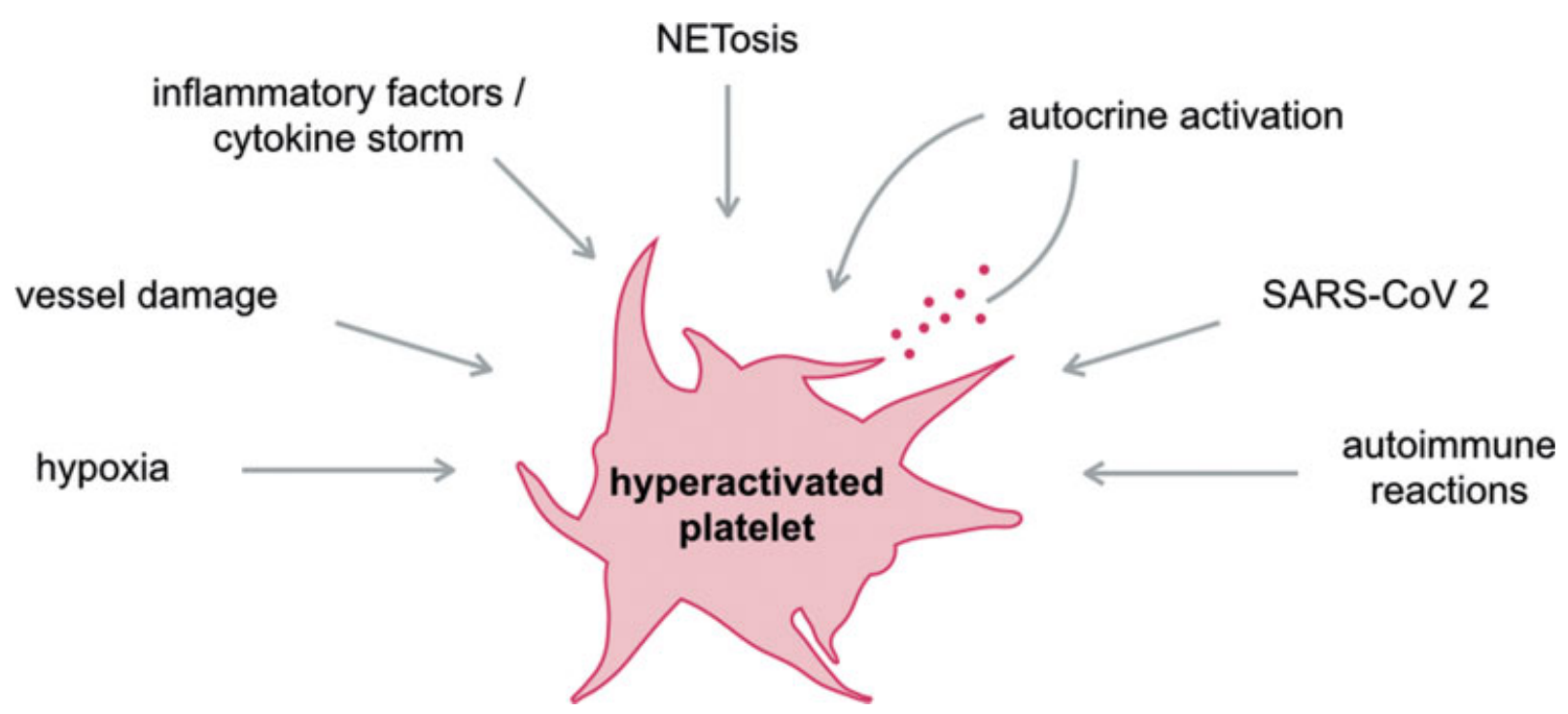

Fig. 2 Hyperactivation of platelets in severe acute respiratory syndrome coronavirus 2 (SARS-CoV-2) infections is due to various inflammatoryinduced factors as well as direct interactions with the SARS-CoV-2 virus.

the subtilisin-like proprotein convertase furin. Cleavage of the SARS-CoV-2 spike protein by furin enhances the binding capabilities and the virus entry into various cell types (-Fig. 1).

In COVID-19 patients, the platelet count differs between mild and serious infections. Patients with mild symptoms have a normal or slightly increased platelet count, whereas thrombocytopenia is a hallmark of severe COVID-19 infections. The low platelet count is an effect of platelet apoptosis and the incorporation of platelets from the peripheral blood into microthrombi and/or severe thrombotic events. The excessive formation of thrombi is at least partly due to hyperactivation of platelets caused by the COVID-19 infections. Various factors are involved in the activation of platelets in COVID-19, such as hypoxia, vessel damage, inflammatory factors like chemokine and cytokines, NETosis, SARS-CoV-2 interaction, autoimmune reactions, and autocrine pathways (-Fig. 2). COVID-19 does alter chemokine and cytokine plasma concentrations. Platelet chemokine profiles are altered in COVID-19 patients and might contribute to the described chemokine storm.

\section{Funding}

This project was supported by the Deutsche Forschungsgemeinschaft (DFG, German Research Foundation)-project number 374031971-TRR 240 (molecular aspects).

\section{Conflict of Interest}

The authors declare that they have no conflict of interest.

\section{References}

1 Wang T, Chen R, Liu C, et al. Attention should be paid to venous thromboembolism prophylaxis in the management of COVID-19. Lancet Haematol 2020;7(05):e362-e363

2 Grobler C, Maphumulo SC, Grobbelaar LM, et al. COVID-19: the rollercoaster of fibrin(ogen), D-dimer, Von Willebrand factor, P- selectin and their interactions with endothelial cells, platelets and erythrocytes. Int J Mol Sci 2020;21(14):E5168

3 Zaid Y, Puhm F, Allaeys I, et al. Platelets can associate with SARSCoV-2 RNA and are hyperactivated in COVID-19. Circ Res 2020; 127(11):1404-1418

4 Al-Samkari H, Karp Leaf RS, Dzik WH, et al. COVID-19 and coagulation: bleeding and thrombotic manifestations of SARSCoV-2 infection. Blood 2020;136(04):489-500

5 Rath D, Petersen-Uribe Á, Avdiu A, et al. Impaired cardiac function is associated with mortality in patients with acute COVID-19 infection. Clin Res Cardiol 2020;109(12):1491-1499

6 Mueller KAL, Langnau C, Günter M, et al. Numbers and phenotype of non-classical $\mathrm{CD} 14{ }^{\mathrm{DIM}} \mathrm{CD} 16^{+}$monocytes are predictors of adverse clinical outcome in patients with coronary artery disease and severe SARS-CoV-2 infection. Cardiovasc Res 2021;117(01): 224-239

7 Koupenova M, Clancy L, Corkrey HA, Freedman JE. Circulating platelets as mediators of immunity, inflammation, and thrombosis. Circ Res 2018;122(02):337-351

8 Huang C, Wang Y, Li X, et al. Clinical features of patients infected with 2019 novel coronavirus in Wuhan, China. Lancet 2020;395 (10223):497-506

9 Young BE, Ong SWX, Kalimuddin S, et al; Singapore 2019 Novel Coronavirus Outbreak Research Team. Epidemiologic features and clinical course of patients infected with SARS-CoV-2 in Singapore. JAMA 2020;323(15):1488-1494

10 Wang W, Xu Y, Gao R, et al. Detection of SARS-CoV-2 in different types of clinical specimens. JAMA 2020;323(18):1843-1844

11 Zhang S, Liu Y, Wang X, et al. SARS-CoV-2 binds platelet ACE2 to enhance thrombosis in COVID-19. J Hematol Oncol 2020;13(01):120

12 Campbell RA, Boilard E, Rondina MT. Is there a role for the ACE2 receptor in SARS-CoV-2 interactions with platelets? J Thromb Haemost 2021;19(01):46-50

13 Bury L, Camilloni B, Castronari R, et al. Search for SARS-CoV-2 RNA in platelets from COVID-19 patients. Platelets 2021;32(02): 284-287

14 Clarke NE, Turner AJ. Angiotensin-converting enzyme 2: the first decade. Int J Hypertens 2012;2012:307315

15 Datta PK, Liu F, Fischer T, Rappaport J, Qin X. SARS-CoV-2 pandemic and research gaps: understanding SARS-CoV-2 interaction with the ACE2 receptor and implications for therapy. Theranostics 2020;10(16):7448-7464 
16 Abassi Z, Knaney Y, Karram T, Heyman SN. The lung macrophage in SARS-CoV-2 infection: a friend or a foe? Front Immunol 2020; $11: 1312$

17 Manne BK, Denorme F, Middleton EA, et al. Platelet gene expression and function in patients with COVID-19. Blood 2020;136 (11):1317-1329

18 Gu SX, Tyagi T, Jain K, et al. Thrombocytopathy and endotheliopathy: crucial contributors to COVID-19 thromboinflammation. Nat Rev Cardiol 2021;18(03):194-209

19 Makowski L, Olson-Sidford W, W-Weisel J. Biological and clinical consequences of integrin binding via a rogue RGD motif in the SARS CoV-2 spike protein. Viruses 2021;13(02):146

20 Sigrist CJ, Bridge A, Le Mercier P. A potential role for integrins in host cell entry by SARS-CoV-2. Antiviral Res 2020;177:104759

21 Shen S, Zhang J, Fang Y, et al. SARS-CoV-2 interacts with platelets and megakaryocytes via ACE2-independent mechanism. J Hematol Oncol 2021;14(01):72

22 Coutard B, Valle C, de Lamballerie X, Canard B, Seidah NG, Decroly E. The spike glycoprotein of the new coronavirus 2019-nCoV contains a furin-like cleavage site absent in $\mathrm{CoV}$ of the same clade. Antiviral Res 2020;176:104742

23 Hoffmann M, Kleine-Weber H, Schroeder S, et al. SARS-CoV-2 cell entry depends on ACE2 and TMPRSS2 and is blocked by a clinically proven protease inhibitor. Cell 2020;181(02):271-280.e8

24 Walls AC, Park YJ, Tortorici MA, Wall A, McGuire AT, Veesler D. Structure, function, and antigenicity of the SARS-CoV-2 spike glycoprotein. Cell 2020;183(06):1735

25 Shang J, Wan Y, Luo C, et al. Cell entry mechanisms of SARS-CoV-2. Proc Natl Acad Sci U S A 2020;117(21):11727-11734

26 Nakayama K. Furin: a mammalian subtilisin/Kex2p-like endoprotease involved in processing of a wide variety of precursor proteins. Biochem J 1997;327(Pt 3):625-635

27 Wang YK, Tang JN, Han L, et al. Elevated FURIN levels in predicting mortality and cardiovascular events in patients with acute myocardial infarction. Metabolism 2020;111:154323

28 Langnau C, Rohlfing AK, Gekeler S, et al. Platelet activation and plasma levels of furin are associated with prognosis of patients with coronary artery disease and COVID-19. Arterioscler Thromb Vasc Biol 2021;41(06):2080-2096

29 Bikdeli B, Madhavan MV, Jimenez D, et al; Global COVID-19 Thrombosis Collaborative Group, Endorsed by the ISTH, NATF, ESVM, and the IUA, Supported by the ESC Working Group on Pulmonary Circulation and Right Ventricular Function. COVID-19 and thrombotic or thromboembolic disease: implications for prevention, antithrombotic therapy, and follow-up: JACC stateof-the-art review. J Am Coll Cardiol 2020;75(23):2950-2973

$30 \mathrm{Bi} \mathrm{X}, \mathrm{Su}$ Z, Yan H, et al. Prediction of severe illness due to COVID-19 based on an analysis of initial fibrinogen to albumin ratio and platelet count. Platelets 2020;31(05):674-679

31 Alnor A, Sandberg MB, Toftanes BE, Vinholt PJ. Platelet parameters and leukocyte morphology is altered in COVID-19 patients compared to non-COVID-19 patients with similar symptomatology. Scand J Clin Lab Invest 2021;81(03):213-217

32 Boeckh-Behrens T, Golkowski D, Ikenberg B, et al. COVID-19associated large vessel stroke in a 28 -year-old patient: NETs and platelets possible key players in acute thrombus formation. Clin Neuroradiol 2021;31(02):511-514
33 Althaus K, Marini I, Zlamal J, et al. Antibody-induced procoagulant platelets in severe COVID-19 infection. Blood 2021;137(08): 1061-1071

34 Saleh J, Peyssonnaux C, Singh KK, Edeas M. Mitochondria and microbiota dysfunction in COVID-19 pathogenesis. Mitochondrion $2020 ; 54: 1-7$

35 Guzik TJ, Mohiddin SA, Dimarco A, et al. COVID-19 and the cardiovascular system: implications for risk assessment, diagnosis, and treatment options. Cardiovasc Res 2020;116(10): 1666-1687

36 Connors JM, Levy JH. COVID-19 and its implications for thrombosis and anticoagulation. Blood 2020;135(23):2033-2040

37 Dib PRB, Quirino-Teixeira AC, Merij LB, et al. Innate immune receptors in platelets and platelet-leukocyte interactions.J Leukoc Biol 2020;108(04):1157-1182

38 Lê VB, Schneider JG, Boergeling Y, et al. Platelet activation and aggregation promote lung inflammation and influenza virus pathogenesis. Am J Respir Crit Care Med 2015;191(07): 804-819

39 Bongiovanni D, Klug M, Lazareva O, et al. SARS-CoV-2 infection is associated with a pro-thrombotic platelet phenotype. Cell Death Dis 2021;12(01):50

40 Colling ME, Kanthi Y. COVID-19-associated coagulopathy: an exploration of mechanisms. Vasc Med 2020;25(05):471-478

41 Zaid Y, Guessous F, Puhm F, et al. Platelet reactivity to thrombin differs between patients with COVID-19 and those with ARDS unrelated to COVID-19. Blood Adv 2021;5(03):635-639

42 Bonaventura A, Vecchié A, Dagna L, et al. Endothelial dysfunction and immunothrombosis as key pathogenic mechanisms in COVID-19. Nat Rev Immunol 2021;21(05):319-329

43 Ackermann M, Verleden SE, Kuehnel M, et al. Pulmonary vascular endothelialitis, thrombosis, and angiogenesis in COVID-19. N Engl J Med 2020;383(02):120-128

44 Gawaz M, Langer H, May AE. Platelets in inflammation and atherogenesis. J Clin Invest 2005;115(12):3378-3384

45 Gawaz M. Role of platelets in coronary thrombosis and reperfusion of ischemic myocardium. Cardiovasc Res 2004;61(03): 498-511

46 Nicolai L, Leunig A, Brambs S, et al. Immunothrombotic dysregulation in COVID-19 pneumonia is associated with respiratory failure and coagulopathy. Circulation 2020;142 (12):1176-1189

47 Ruberto F, Chistolini A, Curreli M, et al; Policlinico Umberto I COVID-19 Group. Von Willebrand factor with increased binding capacity is associated with reduced platelet aggregation but enhanced agglutination in COVID-19 patients: another COVID19 paradox? J Thromb Thrombolysis 2021;52(01):105-110

48 Middleton EA, He XY, Denorme F, et al. Neutrophil extracellular traps contribute to immunothrombosis in COVID-19 acute respiratory distress syndrome. Blood 2020;136(10):1169-1179

49 Cappellano G, Raineri D, Rolla R, et al. Circulating platelet-derived extracellular vesicles are a hallmark of SARS-CoV-2 infection. Cells 2021;10(01):E85

50 Hottz ED, Azevedo-Quintanilha IG, Palhinha L, et al. Platelet activation and platelet-monocyte aggregate formation trigger tissue factor expression in patients with severe COVID-19. Blood 2020;136(11):1330-1341 